\title{
Hidratação do óxido de magnésio em presença de alumina hidratável
}

\section{(Magnesium oxide hydration in presence of hydratable alumina)}

\author{
R. Salomão ${ }^{1}$, M.C.O. Villas-Bôas, V.C.Pandolfelli \\ Grupo de Engenharia de Microestrutura de Materiais, Departamento de Engenharia de Materiais, UFSCar \\ Rod. Washington Luiz, km 235, C.P. 676. S. Carlos, SP 13565-905 \\ ${ }^{1}$ Universidade Federal do ABC, Rua da Catequese, 242, Santo André, SP 09090-400 \\ vicpando@power.ufscar.br,rafael.salomao@ufabc.edu.br
}

\begin{abstract}
Resumo
Aluminas hidratáveis são compostos obtidos a partir da calcinação incompleta da gibsita $\mathrm{Al}(\mathrm{OH})_{3}$, que podem reagir com água e possuem ação ligante em suspensões cerâmicas. A substituição do cimento de aluminato de cálcio pelas aluminas hidratáveis em concretos refratários contendo óxido de magnésio $(\mathrm{MgO})$ pode gerar diversos benefícios em relação às propriedades termomecânicas e refratariedade. No entanto, os efeitos da combinação desses materiais e suas consequiências para a hidratação do $\mathrm{MgO}$ ainda não foram investigados sistemicamente. Neste trabalho, quatro fontes de $\mathrm{MgO}$ e aluminas hidratáveis foram combinadas em diferentes proporções e hidratados simultaneamente. Após investigações utilizando difração de raios X, termogravimetria e expansão volumétrica aparente, verificou-se que a relação $\mathrm{MgO} / \mathrm{Al}_{2} \mathrm{O}_{3}$ e as diferenças de reatividade de cada matéria prima podem afetar significativamente o processo de hidratação. Além disso, foi observado que essa combinação pode ser utilizada como uma interessante técnica anti-hidratação para o $\mathrm{MgO}$.
\end{abstract}

Palavras-chave: óxido de magnésio, alumina hidratável, hidratação, hidrotalcita.

\begin{abstract}
The substitution of calcium aluminate cement by hydratable aluminas in $\mathrm{MgO}$-containing refractory castables can afford several benefits for these materials mechanical properties and refractoriness. Nevertheless, the way that hydratable aluminas affects $\mathrm{MgO}$ hydration and its consequences were not yet systemically explored. In the present work, four sources of magnesia and alumina were combined at different ratios and hydrated simultaneously. They were investigated by X-ray diffraction, thermogravimetry and apparent volumetric expansion measurements. It was found that the magnesia/alumina ratio and the differences of reactivity of each raw material can greatly affect both hydration processes, generating different hydrated compounds. It was also verified that this combination can be suitably used as powerful $\mathrm{MgO}$ anti-hydration technique.
\end{abstract}

Keywords: magnesium oxide, hydratable alumina, hydrotalcite, hydration.

\section{INTRODUÇÃO}

Comumente empregado como ligante hidráulico em formulações de concretos refratários, os cimentos de aluminato de cálcio (CAC) podem aumentar significativamente a expansão volumétrica que acompanha a hidratação do óxido de magnésio ( $\mathrm{MgO}$ ou magnésia) (expansão volumétrica aparente, EVA) e consequentemente, o nível de dano mecânico $[1,2]$. Em suspensões aquosas de sínter de magnésia (SM) ou magnésia cáustica (MC) esse comportamento pode ser associado com a combinação de dois fatores principais [1]: a) a elevação do $\mathrm{pH}$ da suspensão, que aumenta a força motriz para a hidratação do $\mathrm{MgO}$, gerando hidróxido de magnésio $\left(\mathrm{Mg}(\mathrm{OH})_{2}\right.$ ou brucita) e b) a geração de hidrotalcita. A hidrotalcita $\left(\mathrm{Mg}_{6} \mathrm{Al}_{2}(\mathrm{OH})_{16} \mathrm{CO}_{3} \cdot 4 \mathrm{H}_{2} \mathrm{O}\right)$, também conhecida como hidróxido duplo lamelar, é formada quando íons $\mathrm{Mg}^{2+} \mathrm{e} \mathrm{Al}^{3+}$, originários da magnésia e CAC, respectivamente, se combinam em meio aquoso. Sua estrutura é composta por lamelas de hidróxido posi- tivamente carregadas e uma região interlamelar contendo diferentes ânions (geralmente $\mathrm{CO}_{3}{ }^{2-}$ e moléculas de água) (Fig. 1) [3-5]. Devido à sua baixa densidade $\left(\rho_{\text {Brucita }}\right.$ $\left.=2,54 \mathrm{~g} / \mathrm{cm}^{3}>\rho_{\text {Hidrotalcita }}=2,18 \mathrm{~g} / \mathrm{cm}^{3}[4]\right)$, a geração

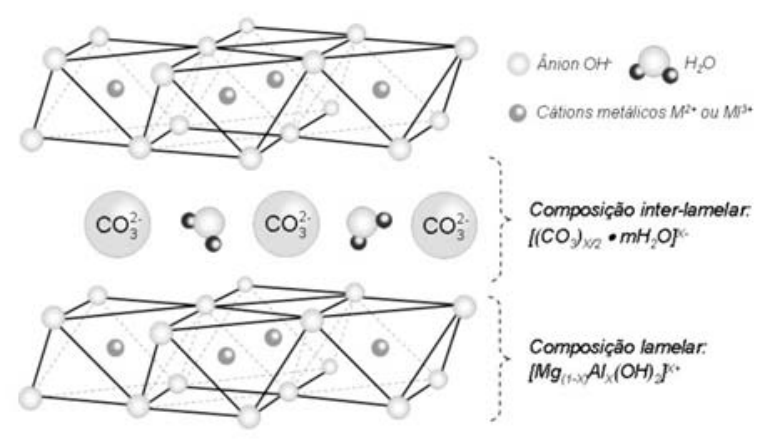

Figura 1: Representação esquemática da estrutura da hidrotalcita $[3,4]$.

[Figure 1: Schematic representation of hydrotalcite structure [3, 4].] 
de hidrotalcita pode causar mais danos por EVA que a simples hidratação do $\mathrm{MgO}$ [1].

Diversos trabalhos registram os benefícios obtidos pela substituição dos CAC por aluminas hidratáveis $(\mathrm{AH})$ em concretos refratários contendo $\mathrm{MgO}$ [6-9]. Além da maior refratariedade garantida pela ausência de compostos com baixo ponto de fusão e pela espinelização in situ [6, 7], essa combinação também leva a outros interessantes efeitos como, menor tempo de endurecimento e melhores propriedades mecânicas antes da sinterização, também atribuídas à hidrotalcita [8,9]. No entanto, apesar do grande interesse tecnológico desses benefícios, os potenciais efeitos colaterais que a geração desse composto pode acarretar em sistemas $\mathrm{MgO}-\mathrm{AH}$ ainda não foram sistemicamente investigados.

Este trabalho teve como objetivo avaliar os vários aspectos da hidratação do $\mathrm{MgO}$ em presença das $\mathrm{AH}$. Suspensões aquosas de $\mathrm{MgO}$ (magnésia cáustica ou sínter de magnésia) contento alumina (alumina hidratável e alumina calcinada) foram simultaneamente expostas à umidade a $50{ }^{\circ} \mathrm{C}$ durante 7 dias. As reações ocorridas e os produtos formados foram acompanhados por meio de difração de raios X, termogravimetria [10] e medidas de expansão volumétrica aparente [2].

\section{MATERIAIS E MÉTODOS}

Suspensões aquosas com diversas proporções de magnésia cáustica ou sínter de magnésia (Magnesita S.A., Brasil) e alumina hidratável (Alphabond 300, Almatis, EUA) ou alumina calcinada (E-Sy 1000, Almatis, EUA) foram preparadas usando o teor de água teórico necessário para hidratar completamente ambos os materiais. Não foram utilizados dispersantes ou outros aditivos. Maiores detalhes das composições podem ser encontrados na Tabela I.

A água e os pós foram previamente resfriados a $10{ }^{\circ} \mathrm{C}$ para inibir uma hidratação prévia da magnésia e, em seguida, misturados durante $3 \mathrm{~min}$. Após a mistura, as suspensões foram vertidas em moldes cilíndricos $(70 \mathrm{~mm} \times 70 \mathrm{~mm})$ para as medidas de expansão volumétrica aparente [2]. O teste de EVA é uma nova técnica desenvolvida para avaliar o nível de dano mecânico causado pela hidratação do $\mathrm{MgO}$ ou pela formação de compostos de baixa densidade e consiste em medir as dimensões das amostras durante a exposição à umidade, durante 7 dias, a $50^{\circ} \mathrm{C}$. O parâmetro EVA é calculado considerando-se o volume inicial das amostras como referência e pode ser descrito pelas expressões:

$$
\begin{aligned}
& \mathrm{V}_{\mathrm{i}}\left(\mathrm{mm}^{3}\right)=\left(\mathrm{H}_{\mathrm{i}} \mathrm{x} \pi \times\left(\mathrm{D}_{\mathrm{i}}-2 \mathrm{t}\right)^{2}\right) / 4 \\
& \operatorname{EVA}(\%)=100 \times\left[\left(\mathrm{V}_{\mathrm{E}}-\mathrm{V}_{0}\right) / \mathrm{V}_{0}\right]
\end{aligned}
$$

A expressão A é utilizada para calcular o volume das amostras cilíndricas em um certo tempo $\left(\mathrm{V}_{\mathrm{i}}\right.$ é o volume, $\mathrm{H}_{\mathrm{i}}$ a altura, $\mathrm{D}_{\mathrm{i}} \mathrm{o}$ diâmetro, $\mathrm{t}$ a espessura da parede do molde). Para o parâmetro EVA, $\mathrm{V}_{0}$ é o volume inicial da amostra e $\mathrm{V}_{\mathrm{E}}$ seu correspondente após a hidratação e expansão. Após esse período de 7 dias, as amostras empregadas nos testes de EVA foram secas em sílica gel, moídas ( $\left.\mathrm{D}_{\text {Part }}<45 \mu \mathrm{m}\right)$ e caracterizadas por meio de difração de raios $\mathrm{X}$ qualitativa (Siemens D5000, radiação Cuk $\alpha$ ) e termogravimetria (25$800{ }^{\circ} \mathrm{C}$, taxa de aquecimento $10{ }^{\circ} \mathrm{C} / \mathrm{min}$ ). Os resultados de DRX são apresentados como a intensidade relativa do pico principal de difração de cada composto identificado (as fontes de $\mathrm{MgO}$ e alumina também foram testadas antes da hidratação como referência). A variação de massa (W, \%peso) e sua taxa (dW/dt, \%/min) foram calculadas por meio das expressões

$$
\begin{gathered}
\mathrm{W}(\%)=100 \times\left(\left(\mathrm{M}_{0}-\mathrm{M}\right) /\left(\mathrm{M}_{0}-\mathrm{M}_{\mathrm{F}}\right)\right) \\
(\mathrm{dW} / \mathrm{dt})_{\mathrm{i}}(\% / \mathrm{min})=\left(\mathrm{W}_{(\mathrm{i}+10)}-\mathrm{W}_{(\mathrm{i}-10)}\right) /\left(\mathrm{t}_{(\mathrm{i}+10)}-\mathrm{t}_{(\mathrm{i}-10)}\right)
\end{gathered}
$$

nas quais $M$ é a massa instantânea registrada em um determinado tempo $t_{i}$ durante o aquecimento, $\mathrm{M}_{0}$ a massa

\begin{tabular}{|c|c|c|c|c|}
\hline $\begin{array}{l}\text { Características das } \\
\text { matérias-primas }\end{array}$ & $\begin{array}{c}\text { Magnésia } \\
\text { cáustica* }(\mathrm{MC})\end{array}$ & $\begin{array}{c}\text { Sínter de magnésia* } \\
\text { (SM) }\end{array}$ & $\begin{array}{l}\text { Alumina } \\
\text { hidratável** } \\
\text { (AH) }\end{array}$ & $\begin{array}{l}\text { Alumina } \\
\text { calcinada** } \\
\text { (AC) }\end{array}$ \\
\hline$\%$ peso de $\mathrm{MgO}$ ou $\mathrm{Al}_{2} \mathrm{O}_{3}$ & $99,5^{\mathbf{\Delta}}$ & $98,38^{\mathbf{4}}$ & $88,2^{\mathbf{4}}$ & $99,4^{\mathbf{\Lambda}}$ \\
\hline Densidade $\left(\mathrm{g} / \mathrm{cm}^{3}\right)$ & 3,52 & 3,56 & 2,77 & 3,95 \\
\hline Área superficial $\left(\mathrm{m}^{2} / \mathrm{g}\right)$ & 20 & 1,2 & 180 & 3,33 \\
\hline Diâmetro médio $(\mu \mathrm{m})$ & 100 & 15 & 6 & 25 \\
\hline \%peso nas suspensões & & $0-100$ & & \\
\hline $\begin{array}{c}\text { Teor de água } \\
\text { (\%peso sobre massa seca) }\end{array}$ & \multicolumn{4}{|c|}{$44,6-51,6$} \\
\hline
\end{tabular}
inicial, $\mathrm{M}_{\mathrm{F}}$ a massa final da amostra testada $[2,10]$.

Tabela I - Suspensões de magnésia-alumina.

[Table I - Magnesia-alumina suspensions.]

* Magnesita S.A. (Brasil); ** Almatis (EUA); ^ Valores típicos. 


\section{RESULTADOS E DISCUSSÃO}

Componentes hidratados separadamente e hidratação das fontes de $\mathrm{MgO}$ em presença de alumina calcinada

Inicialmente, os processos de hidratação de cada componente foram investigados individualmente (suspensões contendo $100 \%$ peso de cada matéria prima e o teor de água teórico para propiciar sua total hidratação). Comparando os resultados de DRX (Figs. 2a e 2b), EVA(Fig. 3a) e TG (Fig. $3 b)$ para diferentes fontes de $\mathrm{MgO}$, pode-se observar que sob uma mesma condição de hidratação a EVA iniciou-se antes e mais intensamente para a MC que para o SM. Além disso, enquanto aquela reagiu quase que estequiometricamente com a água gerando brucita, o SM atingiu apenas $70 \%$ do valor teórico do grau de hidratação. Esse comportamento pode ser atribuído a dois fatores principais. Comparada ao SM, a MC apresenta uma estrutura cristalina mais defeituosa, com cristais pequenos (tamanho médio de cristal da ordem de 2 $\mu \mathrm{m})$ e numerosos contornos de grão e maior área superficial $[1,11]$. Essas características aumentam a área de contato com a água e sua reatividade, favorecendo a hidratação, com maior nível de EVA. O SM, por outro lado, durante sua produção é aquecido a $1600{ }^{\circ} \mathrm{C}$, favorecendo a recuperação da estrutura cristalina do periclásio e o crescimento de grãos (tamanho médio de cristal de $\sim 10 \mu \mathrm{m}$ ), o que reduz sua reatividade. Não foi verificada evidência significativa de hidratação para a AC (Figs. 2c e 3c), enquanto que para a $\mathrm{AH}$, um elevado grau de hidratação foi observado devido à geração de boemita (Figs. 2d e 3c). Como discutido para as fontes de $\mathrm{MgO}$, essas diferenças podem ser atribuídas à área superficial e à cristalinidade das fontes de alumina. A $\mathrm{AC}$ é composta principalmente de fase $\alpha$-alumina de alta cristalinidade e quimicamente inerte. A AH, por outro lado, é uma fase menos cristalina da alumina ( $\rho$-alumina). Devido a isso e à sua grande área superficial, a $\mathrm{AH}$ reagiu mais intensamente com a água do que seu equivalente calcinado $[6,7]$. Nenhuma evidência de EVA foi observada para esses materiais (Fig. 3a).

A introdução de $\mathrm{AC}$ em ambas as fontes de $\mathrm{MgO}$ reduziu o valores de EVA, como mostrado nas Figs. 4a e 5a. No entanto, como o aumento da fração de AC também causou a redução simultânea nas intensidades dos picos de difração da brucita e periclásio (Figs. 4b e 5b), pode-se afirmar que esse efeito não foi causado por uma possível redução da velocidade de hidratação do $\mathrm{MgO}$. Considerando-se os resultados das Figs. 2c e 3c, esse comportamento pode ser associado à inércia química da AC (nas condições empregadas nos testes). Como não foi observada a geração de compostos hidratados (como boemita, $\mathrm{AlO}(\mathrm{OH})$ ) e,

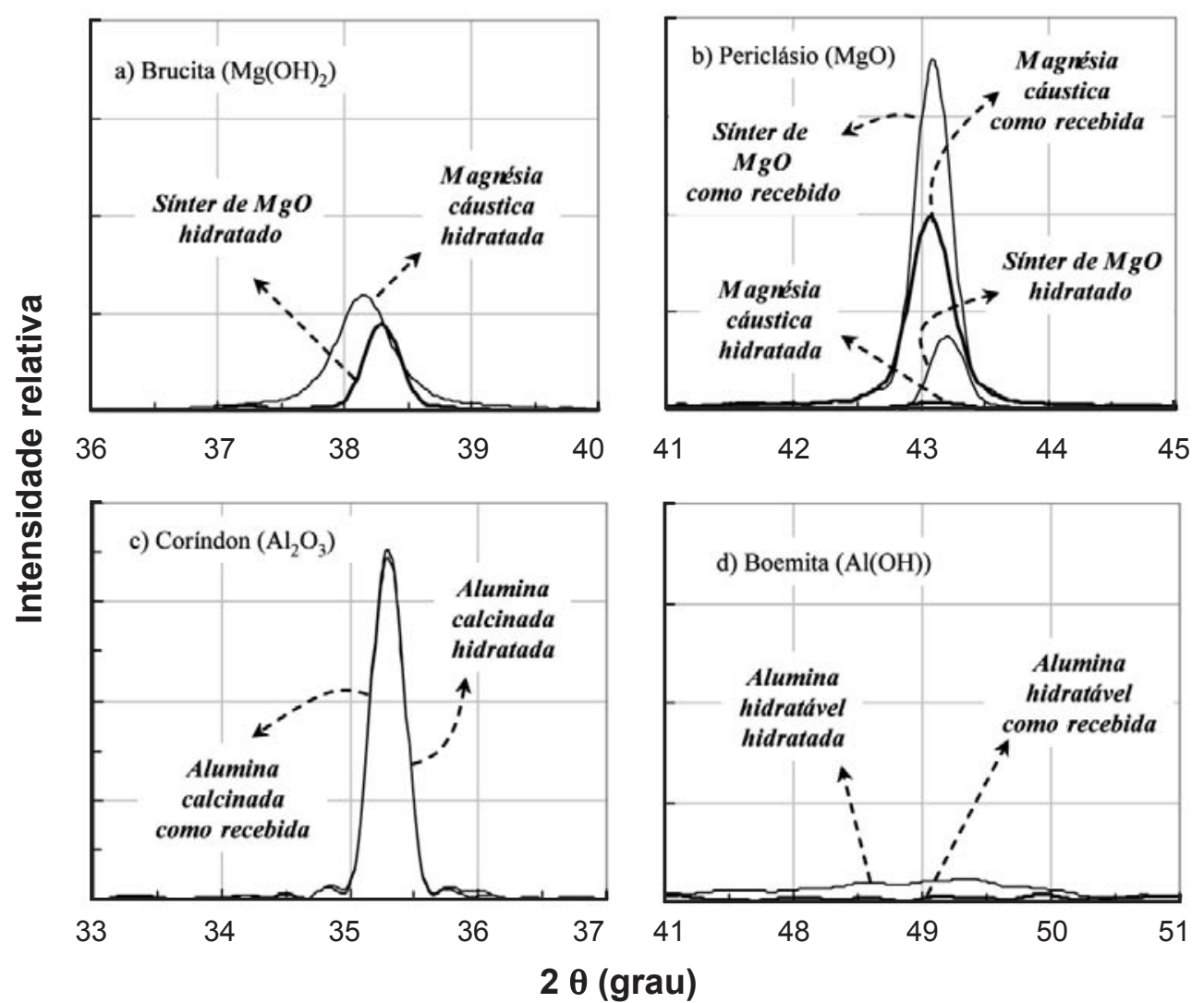

Figura 2: Difratogramas de raios $\mathrm{X}$ das fontes de $\mathrm{MgO}$ (a e b) e $\mathrm{Al}_{2} \mathrm{O}_{3}$ (c e d) hidratadas separadamente (após 7 dias, a $50{ }^{\circ} \mathrm{C}$ em ambiente úmido).

[Figure 2: X-ray diffraction patterns of the $\mathrm{MgO}$ sources ( $a$ and $b$ ) and $\mathrm{Al}_{2} \mathrm{O}_{3}(c$ and $d$ ) separately hydrated (after 7 days, at $50^{\circ} \mathrm{C}$, in humid environment).] 


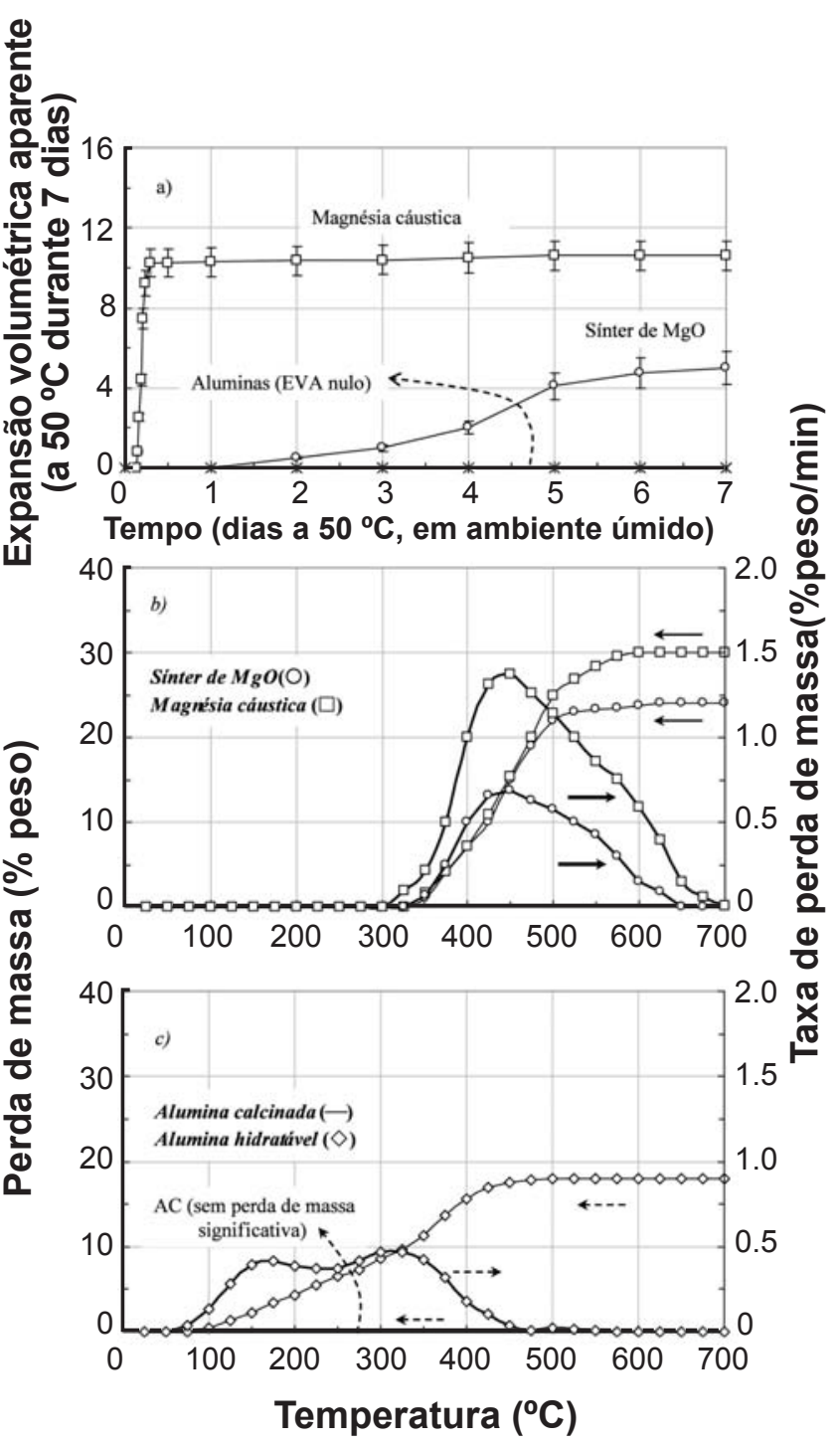

Figura 3: a) Expansão volumétrica aparente (EVA) para suspensões $100 \% \mathrm{MgO}$ e termogravimetria das fontes de b) $\mathrm{MgO}$ e c) $\mathrm{Al}_{2} \mathrm{O}_{3}$ hidratadas separadamente (após 7 dias a $50{ }^{\circ} \mathrm{C}$, em ambiente úmido).

[Figure 3: a) apparent volumetric expansion for 100 wt.\% of $\mathrm{MgO}$ and thermogravimetry of the sources of b) $\mathrm{MgO}$ and c) $\mathrm{Al}_{2} \mathrm{O}_{3}$ separately hydrated (after 7 days, at $50{ }^{\circ} \mathrm{C}$, in humid environment).]

consequentemente, nenhuma dissolução significativa de íons $\mathrm{Al}^{3+}$ verificada, as fontes de $\mathrm{MgO}$ se hidrataram como se estivessem em presença de uma substancia inerte e o menor valor de EVA resultou simplesmente da redução do teor volumétrico de $\mathrm{MgO}$ na composição das suspensões [1].

Hidratação da magnésia cáustica em presença de alumina hidratável

Quando as fontes de $\mathrm{MgO}$ foram hidratadas em presença da $\mathrm{AH}$, diferentes efeitos foram observados em relação às hidratações individuais ou em presença de AC (mostrados de forma esquemática na Fig. 6). Para as suspensões de MC, na amostra sem $\mathrm{AH}$, quase todo o $\mathrm{MgO}$ foi convertido em brucita e uma pequena quantidade de periclásio permaneceu

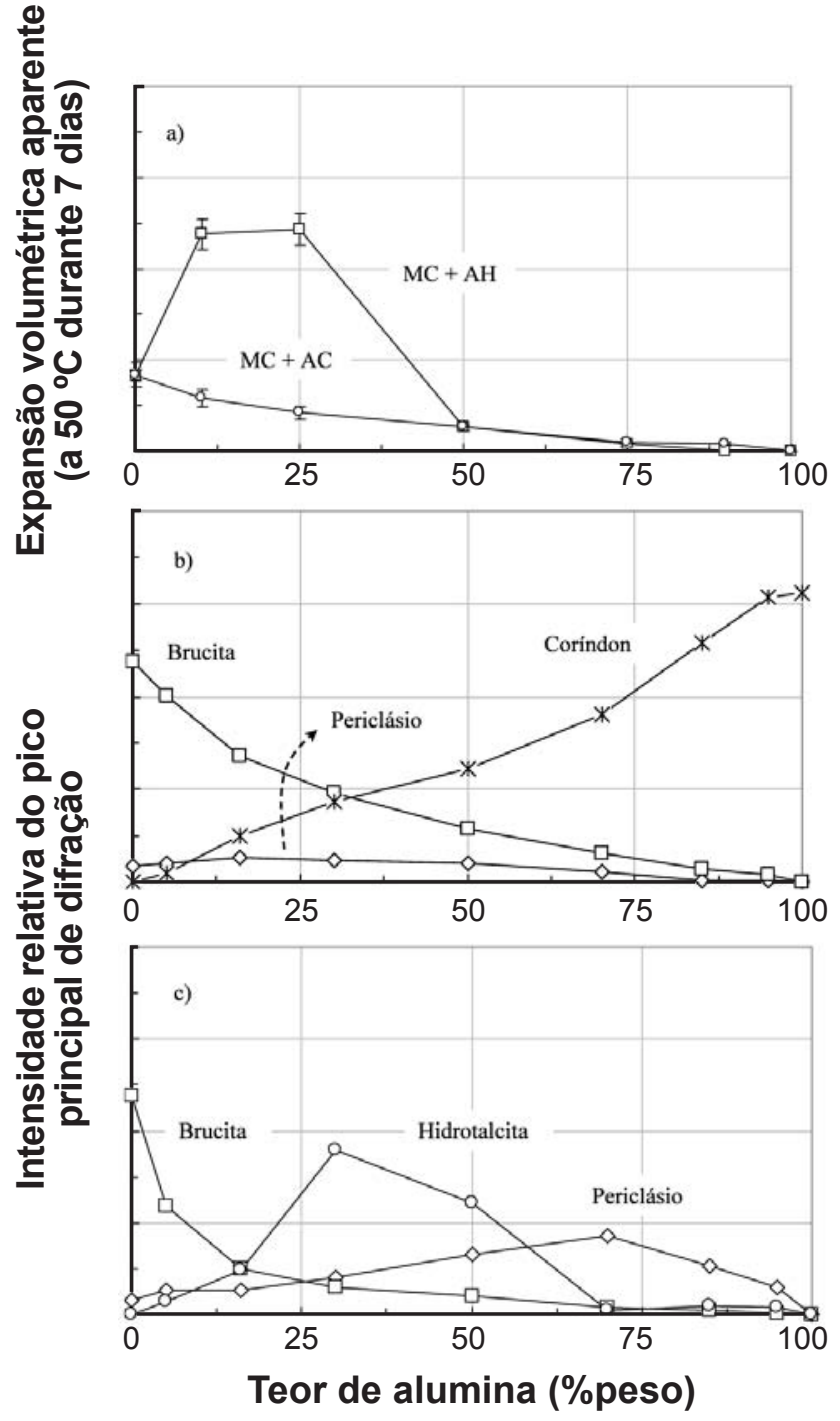

Figura 4: a) Expansão volumétrica aparente e resultados de difração de raios $\mathrm{X}$ para suspensões de magnésia cáustica contendo b) alumina calcinada ou c) alumina hidratável após 7 dias a $50{ }^{\circ} \mathrm{C}$ em ambiente úmido).

[Figure 4: a) Apparent volumetric expansion and X-ray diffraction results for caustic magnesia suspensions containing b) calcined alumina or c) hydratable alumina after 7 days at $50^{\circ} \mathrm{C}$, in humid environment.]

não reagida (Figs. 2a, 2b e 6a). Para adição de $\mathrm{AH}$ de 10 a $25 \%$ peso, um grande aumento nos valores de expansão volumétrica aparente foram observados (Fig. 4a), ao mesmo tempo em que a intensidade do pico de periclásio não foi afetada significativamente e o de brucita foi reduzido devido à geração de hidrotalcita (Fig. 4c).

A hidrotalcita é gerada quando íons $\mathrm{Al}^{3+}$ substituem alguns dos $\mathrm{Mg}^{2+}$ na estrutura da brucita, resultando em uma folha de octaedros de hidróxido de alumínio e magnésio que recebe uma carga positiva a cada $\mathrm{Al}^{3+}$ adicionado (os ânions localizados entre as folhas de hidróxido e moléculas de água mantêm a neutralidade elétrica do material) [3, 4]. Com base nesse mecanismo, pode-se afirmar que a redução na intensidade do pico da brucita ocorreu porque, em excesso 

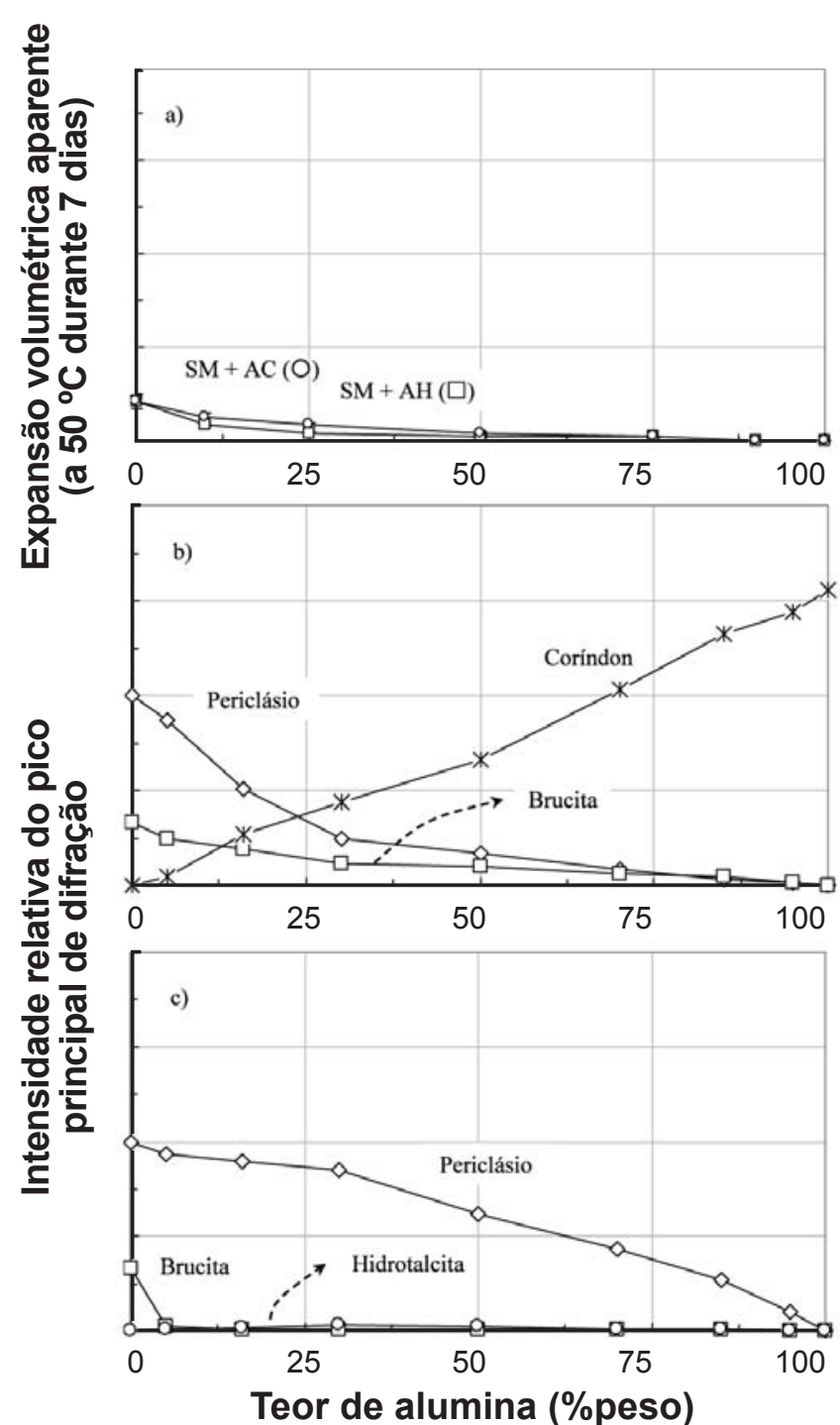

Figura 5: a) Expansão volumétrica aparente e resultados de difração de raios $X$ para suspensões de sínter de magnésia contendo b) alumina calcinada ou c) alumina hidratável (após 7 dias a $50{ }^{\circ} \mathrm{C}$ em ambiente úmido). [Figure 5: a) Apparent volumetric expansion and X-ray diffraction results for magnesia sinter suspensions containing b) calcined alumina and c) hydratable alumina (after 7 days at $50^{\circ} \mathrm{C}$ in humid environment).]

de $\mathrm{MgO}$, uma parte significativa dos íons $\mathrm{Mg}^{2+}$ liberados para a solução não foi convertida em brucita e sim consumidos preferencialmente na geração de hidrotalcita. Quanto o teor de AH atingiu a estequiometria da hidrotalcita (razão 3:1 entre íons $\mathrm{Mg}^{2+}$ e $\mathrm{Al}^{3+}$ ou por volta de 25-30 \% peso de $\mathrm{AH}$ $[3,4]$ ), foram observados os valores máximos de EVA (Fig. 4a) e da intensidade do pico de hidrotalcita (Figs. 4c e 6b). Os elevados valores de EVA (significativamente maiores que os observados para a brucita) podem ser associados à menor densidade da hidrotalcita e ao maior espaçamento entre suas lamelas $\left(\mathrm{h}_{\text {Brucita }}=3,4 \AA ; \mathrm{h}_{\text {Hidrotalcita }}=23 \AA\right.$ ) [4]. Para teores de $\mathrm{AH}$ maiores que $25 \%$ peso, os resultados de DRX indicam a presença de boemita. No entanto, devido

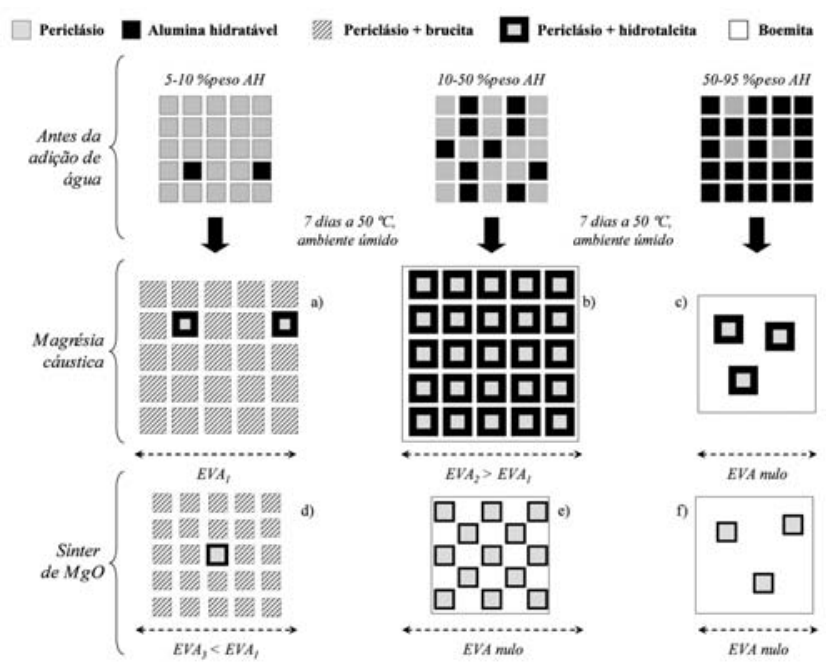

Figura 6: Representação esquemática das interações entre alumina hidratável e magnésia cáustica ou alumina hidratável e sínter de magnésia.

[Figure 6: Schematic representation of the interactions between hydratable alumina and caustic magnesia or magnesia sinter.]

à sua baixa cristalinidade [6], ela não pode ser quantificada adequadamente por essa técnica. Além disso, a intensidade do pico de hidrotalcita foi reduzida, enquanto a do periclásio atingiu seu valor máximo a $70 \%$ peso de $\mathrm{AH}$ (Fig. 4c). Quando a AH é o componente majoritário, há um excesso de íons $\mathrm{Al}^{3+}$ na suspensão. Parte deles é consumida na geração de boemita e, para seguir a estequiometria da reação, a hidrotalcita é gerada nas regiões com maior concentração de $\mathrm{Mg}^{2+}$ [9], ou seja, na superfície das partículas de MgO [11]. A estrutura resultante é provavelmente formada por uma abundante matriz de boemita que envolve as partículas de $\mathrm{MgO}$ recobertas por hidrotalcita (Fig. 6c). Como a própria camada de hidrotalcita atua reduzindo a taxa de difusão dos íons $\mathrm{Mg}^{2+}$ para a suspensão [3], a geração de mais hidrotalcita é interrompida e, devido a isso, a parte interior das partículas de $\mathrm{MgO}$ permanece não reagida e sem causar um aumento na EVA (Fig. 4a).

Hidratação do sínter de $\mathrm{MgO}$ em presença de alumina hidratável

Os resultados de DRX (Fig. 5c) indicam que para teores de $\mathrm{AH}$ maiores que 5\%peso a intensidade do pico de periclásio decresce suavemente com o aumento da fração de $\mathrm{AH}$, ao mesmo tempo em que não se detectaram sinais de brucita, hidrotalcita ou geração de EVA (Figs. 5a e 6d). Como demonstrado nas seções anteriores, o SM apresenta uma reatividade química significativamente menor que a $\mathrm{MC}$ e nesse caso, além disso, menor área superficial. Isso significa que em contato com água poucos ions $\mathrm{Mg}^{2+}$ são liberados e estão disponíveis para gerar hidrotalcita [11]. Devido a isso, mesmo pequenas quantidades de $\mathrm{AH}$ são suficientes para gerar camadas de hidrotalcita nas superfícies das partículas de SM e interromper sua reação (traços de hidrotalcita foram detectados via DRX). A diminuição 
contínua da intensidade do pico do periclásio (Fig. 5c), por outro lado, está relacionada à variação volumétrica da fração de $\mathrm{MgO}$ na composição (Figs. 6e e 6f) [1].

\section{CONCLUSÕES}

Os efeito da adição de alumina hidratável na hidratação de diferentes fontes de $\mathrm{MgO}$, magnésia cáustica ou sínter de $\mathrm{MgO}$ foram investigados. A presença de alumina hidratável afetou significativamente o comportamento de hidratação da magnésia cáustica e do sínter de $\mathrm{MgO}$. Em combinação com o $\mathrm{MgO}$, a alumina hidratável favoreceu a geração de hidrotalcita $\left(\mathrm{Mg}_{6} \mathrm{Al}_{2}(\mathrm{OH})_{16} \mathrm{CO}_{3} \cdot 4 \mathrm{H}_{2} \mathrm{O}\right)$ devido à grande disponibilidade de íons $\mathrm{Mg}^{2+} \mathrm{e} \mathrm{Al}^{3+}$. Dependendo do teor de hidrotalcita gerado, ele pode atuar como uma barreira protetora contra a hidratação do $\mathrm{MgO}$ ou gerar níveis de expansão volumétrica aparente muito maiores que aqueles produzidos pela brucita devido à sua menor densidade. A maior reatividade da magnésia cáustica causou à geração de grande quantidade de hidrotalcita e níveis elevados de expansão volumétrica aparente, especialmente para as amostras contendo 70-90 \%peso de $\mathrm{MgO}$. Naquelas com SM, por outro lado, a hidrotalcita foi gerada na superfície das partículas, atuando como camada protetora e reduzindo a velocidade e os efeitos da hidratação do $\mathrm{MgO}$. Para ambas as fontes de $\mathrm{MgO}$ foi demonstrado com o uso de amostras de referência onde a alumina hidratável foi substituída por outra matéria prima quimicamente inerte (alumina calcinada), que os valores de expansão volumétrica aparente podem ser reduzidos sem que a cinética de hidratação do $\mathrm{MgO}$ tenha sido afetada.

\section{AGRADECIMENTOS}

Os autores agradecem à FAPESP, Alcoa Alumínio e Magnesita S.A. pelo suporte fornecido a este trabalho.

\section{REFERÊNCIAS}

[1] R. Salomão, L. F. Amaral, V. C. Pandolfelli, “Adição de cimento de aluminato de cálcio e seus efeitos na hidratação do óxido de magnésio (MgO)" Cerâmica 56, 338 (2010) 134-139.

[2] R. Salomão, L. R. M. Bittencourt, V. C. Pandolfelli, "A novel approach for magnesia hydration assessment in refractory castables", Ceram. Int. 33, 5 (2007) 803-810.

[3] W. T. Reichle, "Anionic clay minerals", Chemtech $\mathbf{1 6}$ (1986) 58-63.

[4] A. Vaccari, "Clays and catalysis: a promising future", Appl. Clay Sci. 14 (1999) 161-198.

[5] K. G. Ahari, J. H. Sharp, W. E. Lee, "Hydration of refractory oxides in castable bond system - I: Alumina, magnesia and alumina-magnesia mixtures", J. Eur. Ceram. Soc. 22 (2002) 495-503.

[6] Y. Hongo, "Rho-alumina bonded castable refractories", Taikabutsu Overseas 9, 1 (1988) 35-38.

[7] W. Ma, P. Brown, "Mechanisms of reaction of hydratable aluminas", J. Am. Ceram. Soc. 82, 2 (1999) 453-456.

[8] G. Ye, T. Troczynski, "Effect of magnesia on strength of hydratable alumina-bonded castable refractories", J. Mater. Sci. 40 (2005) 3921-3926.

[9] G. Ye, T. Troczynski, "Hydration of hydratable alumina in the presence of various forms of $\mathrm{MgO}$ ", Ceram. Int. 32 (2006) 257-262.

[10] F. A. Cardoso, M. D. M. Innocentini, M. F. S. Miranda, F. A. O. Valenzuela, V. C. Pandolfelli, "Drying behavior of hydratable alumina-bonded refractory castables", J. Eur. Ceram. Soc. 24 (2004) 797-802.

[11] S. D. F. Rocha, M. B. Mansur, V. S. T. Ciminelli, "Kinetics and Mechanistic Analysis of Caustic Magnesia Hydration", J. Chem. Techn. Biotech. 79, 8 (2004) 816-821. (Rec. 21/04/2008, Ac. 05/12/2008) 